\title{
A Facile Co-Deposition Approach to Construct Functionalized Graphene Quantum Dots Self-Cleaning Nanofiltration Membranes
}

\author{
Tong Yu ${ }^{1}$, Chenpu Wu ${ }^{1,2}$, Zhongyan Chen ${ }^{1,2}$, Mingen Zhang ${ }^{1,3}$, Zhuan Hong ${ }^{1,3}$, Honghui Guo 1,3®D, \\ Wenyao Shao $^{2, *}$ and Quanling Xie ${ }^{1,3, * \text { (D) }}$ \\ 1 Technology Innovation Center for Exploitation of Marine Biological Resources, Third Institute of \\ Oceanography, Ministry of Natural Resources, Xiamen 361005, China; yutongtx_1@163.com (T.Y.); \\ darrenwu.cp@foxmail.com (C.W.); 20420201151646@stu.xmu.edu.cn (Z.C.); 18859551701@163.com (M.Z.); \\ zhong@tio.org.cn (Z.H.); hhguo@tio.org.cn (H.G.) \\ 2 Department of Chemical and Biochemical Engineering, College of Chemistry and Chemical Engineering, \\ Xiamen University, Xiamen 361005, China \\ 3 Fujian Collaborative Innovation Center for Exploitation and Utilization of Marine Biological Resources, \\ Xiamen 361005, China \\ * Correspondence: wyshao@xmu.edu.cn (W.S.); qlxie@tio.org.cn (Q.X.)
}

\section{check for} updates

Citation: Yu, T.; Wu, C.; Chen, Z.; Zhang, M.; Hong, Z.; Guo, H.; Shao, W.; Xie, Q. A Facile Co-Deposition Approach to Construct Functionalized Graphene Quantum Dots Self-Cleaning Nanofiltration Membranes. Nanomaterials 2022, 12, 41. https://doi.org/10.3390/nano 12010041

Academic Editor: Minas M. Stylianakis

Received: 23 November 2021 Accepted: 19 December 2021 Published: 23 December 2021

Publisher's Note: MDPI stays neutral with regard to jurisdictional claims in published maps and institutional affiliations.

Copyright: (C) 2021 by the authors. Licensee MDPI, Basel, Switzerland. This article is an open access article distributed under the terms and conditions of the Creative Commons Attribution (CC BY) license (https:// creativecommons.org/licenses/by/ $4.0 /)$.

\begin{abstract}
In this study, a novel photocatalytic self-cleaning nanofiltration (NF) membrane was fabricated by constructing aspartic acid-functionalized graphene quantum dots (AGQDs) into the polydopamine/polyethyleneimine (PDA/PEI) selective layer via the co-deposition method. The chemical composition, microstructure, and hydrophilicity of the prepared membranes were characterized by scanning electron microscopy (SEM), atomic force microscopy (AFM), attenuated total reflection (ATR-FTIR), X-ray photoelectron spectroscopy (XPS), and water contact angle (WCA). Meanwhile, the effects of PEI molecular weight and AGQDs concentration on NF membrane structures and separation performance were systematically investigated. The photocatalytic self-cleaning performance of the PDA/PEI/AGQDs membrane was evaluated in terms of flux recovery rate. For constructing high-performance NF membranes, it is found that the optimal molecular weight of PEI is $10,000 \mathrm{Da}$, and the optimal concentration of AGQDs is $2000 \mathrm{ppm}$. The introduction of hydrophilic AGQDs formed a more hydrophilic and dense selective layer during the co-deposition process. Compared with the PDA/PEI membrane, the engineered PDA/PEI/AGQDs NF membrane has enhanced water flux (55.5 LMH $\left.\cdot \mathrm{bar}^{-1}\right)$ and higher rejection ( $99.7 \pm 0.3 \%$ for $\left.\mathrm{MB}\right)$. In addition, the PDA/PEI/AGQDs membrane exhibits better photocatalytic self-cleaning performance over the PDA/PEI membrane ( $83 \%$ vs. $69 \%$ ). Therefore, this study provides a facile approach to construct a self-cleaning NF membrane.
\end{abstract}

Keywords: nanofiltration; graphene quantum dots; L-aspartic acid; self-cleaning; co-deposition

\section{Introduction}

The environmental hazards of dye wastewater should not be underestimated. Membrane separation technology has the advantage of energy-saving and high efficiency, which is widely applied to treat dye wastewater. However, membrane fouling is a critical issue limiting the application of membrane separation technology in dye treatment, which increases costs and reduces efficiency. Photocatalytic self-cleaning membranes provide a possible solution [1,2]. Photocatalytic self-cleaning membranes are commonly prepared by introducing nanoparticles with photocatalytic properties, which can degrade contaminants on the membrane surface by light irradiation [3-6]. On the one hand, the degradation of pollutants by light irradiation improves the efficiency of the membrane cleaning process. On the other hand, self-cleaning achieves membrane reuse, improves membranes' antifouling performance, and reduces membrane loss and costs. More and more researchers are devoted to developing high-performance photocatalytic self-cleaning NF membranes. 
Dopamine (DA), often referred to as "bio-glue", is widely used for the surface functionalization of different substrate membranes [7]. Under alkaline conditions, dopamine is readily oxidized to form polydopamine (PDA) with strong adhesion [8], which enhances the stability of the membrane by strongly binding to the substrate. In addition, the unique chemical properties of PDA can act as a free-radical scavenger to protect the composite nanofiltration (NF) membrane [9,10]. Shao et al. [11] prepared self-cleaning NF membranes by constructing a PDA/GQDs interlayer using the interfacial polymerization method, and the fabricated NF membranes containing GQDs could effectively degrade organic molecules. The encapsulation of GQDs by the PDA/GQDs interlayer may play a crucial role in preventing the catalytic performance of GQDs from deactivating. However, PDA would easily be damaged under a strongly alkaline environment. At the same time, the long-term self-polymerization process of PDA on the membrane surface tends to block membrane pores [12], which is hindering the application of PDA in the membrane field.

Polyethyleneimine (PEI) can react with PDA through Michael addition or Schiff base reaction, thus mitigating the self-polymerization process of PDA on the membrane surface [13]. The co-deposition of PDA with PEI on the surface of polyphenylene sulfide (PPS) membranes facilitates the construction of NF membranes with high hydrophilicity, acid and alkaline resistance, and high dye separation [13]. Lv et al. [14] used a biomimetic mineralization method to grow $\beta$-FeOOH nanorods on a co-deposited PDA-PEI layer. Due to the strong coordination of $\mathrm{Fe}^{3+}$ and catechol groups, the PDA-PEI layer can serve as the selective layer for NF membranes and provide a spot to anchor the growth of $\beta$ $\mathrm{FeOOH}$ nanorods, resulting in the excellent self-cleaning property of the fabricated NF membrane. As a new type of zero-dimensional nanomaterial, graphene quantum dots (GQDs) also have the property of photocatalytic degradation of dyes [15,16]. Compared with $\beta$-FeOOH, GQDs with small sizes can form a more uniform membrane surface [11,17]. The functionalization of GQDs with aspartic acid is expected to improve the hydrophilicity and further enhance the photocatalytic performance of GQDs $[18,19]$.

Herein, we fabricated a photocatalytic self-cleaning NF membrane by introducing AGQDs into the PDA/PEI composite layer via a green and environment-friendly codeposition method. The chemical cross-linking of PDA and PEI enhanced the stability of the selective layer of the NF membrane [20]. AGQDs impart self-cleaning ability to the PDA/PEI/AGQDs membrane, which effectively degrades the enriched methyl blue molecules on the membrane surface. Furthermore, our work has optimized the molecular weight of PEI and determined the best introducing concentration of AGQDs in the PDA/PEI substrate, which would have a significant reference for dyes removal by NF membranes.

\section{Materials and Methods}

\subsection{Materials}

Citric acid (CA, $98 \%$ purity), caustic soda ( $\mathrm{NaOH}, 99 \%$ purity), and hydrochloric acid $(\mathrm{HCl}, 37 \%$ purity) were purchased from Sinopharm Chemical Reagent Company (Shanghai, China). L-aspartic acid (>98\% purity) and dopamine hydrochloride were purchased from Sigma-Aldrich Trading Co. Ltd. (Shanghai, China). PEI (Mw $=600 \mathrm{Da}, \mathrm{Mw}=1800 \mathrm{Da}$, $\mathrm{Mw}=10 \mathrm{kDa}$ ) was produced by Shanghai Macklin Biochemical Co., Ltd. (Shanghai, China). Methyl blue (MB, 1\% purity), methyl orange (MO, 99\% purity), Congo red (CR, 78\% purity), and Rhodamine B (RhB, 99\% purity) were purchased from Shanghai Aladdin (Shanghai, China). The polyethersulfone ( $\mathrm{PES}, \mathrm{Mw}=10 \mathrm{kDa}$ ) substrate was provided by Shanghai Mosu Science Equipment Co., Ltd. (Shanghai, China).

\subsection{Synthesis of AGQDs}

As shown in Figure 1, AGQDs were synthesized by a one-step hydrothermal method [21]. Briefly, $10 \mathrm{~g}$ of CA and a certain amount of L-aspartic acid were mixed into $50 \mathrm{~mL}$ of deionized water. The mixture was ultrasonicated for $30 \mathrm{~min}$ to ensure a homogeneous mixture. Then, the mixture was heated at $200{ }^{\circ} \mathrm{C}$ for $120 \mathrm{~min}$, during which time CA and L-aspartic acid reacted. The solution gradually changes from colorless to red-orange, 
indicating the formation of AGQDs. Subsequently, the solution was neutralized using $1 \mathrm{M} \mathrm{NaOH}$. The neutralized solution was purified in a dialysis bag (1000 Da) for $24 \mathrm{~h}$ to remove unreacted reactants. Finally, the purified solution was freeze-dried to obtain AGQDs powder. The pristine GQDs were synthesized and purified by the same method except using CA as raw material.

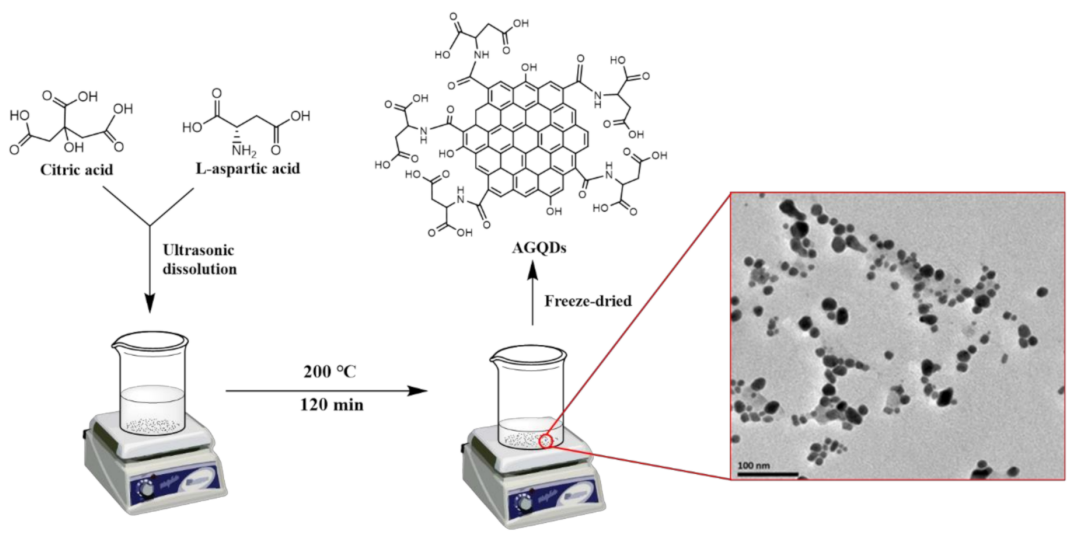

Figure 1. Scheme of the synthetic process of AGQDs.

\subsection{Preparation of NF Membranes}

The NF membranes were prepared by the co-deposition method using physical pressurization. The specific steps are as follows:

a. The polyethersulfone (PES) substrate was immersed in deionized water for $30 \mathrm{~min}$ to remove the protective solution and then dried naturally.

b. Then, we prepared $200 \mathrm{~mL}$ of $2 \mathrm{mg} / \mathrm{mL}$ aqueous solution of dopamine hydrochloride. Tris-buffer was added into PDA solution to adjust $\mathrm{pH}$ to 8.5. After that, different amounts of AGQDs and a certain amount of PEI were added to the solution. The mixed solution was stirred at room temperature for $2 \mathrm{~h}$ to obtain the homogeneous aqueous solution in the co-deposition reaction.

c. We fixed the PES substrate on a stirred cell ultrafiltration device (Millipore ${ }^{\circledR}$ Amicon, Billerica, MA, USA); then, $100 \mathrm{~mL}$ of PDA/PEI/AGQDs mixed solution was added to perform pressurized filtration under the pressure of $0.2 \mathrm{MPa}$ at $25^{\circ} \mathrm{C}$.

d. Afterward, the unreacted PDA on the membrane surface was washed with deionized water. After being dried at $50{ }^{\circ} \mathrm{C}$ for $15 \mathrm{~min}$, the fabricated membrane was used for characterization and performance testing.

The prepared membranes definitions and the concrete co-deposition conditions are shown in Table 1.

Table 1. The co-deposition reaction conditions of TFC and TFN NF membranes.

\begin{tabular}{cccccc}
\hline Membranes & $\begin{array}{c}\text { PDA } \\
\text { Concentration } \\
(\boldsymbol{\%} w / \boldsymbol{w})\end{array}$ & PEI Mw (Da) & $\begin{array}{c}\text { PEI } \\
\text { Concentration } \\
(\mathbf{\%} \boldsymbol{w} / \boldsymbol{v})\end{array}$ & $\begin{array}{c}\text { AGQDs } \\
(\mathbf{p p m})\end{array}$ & $\begin{array}{c}\text { Temperature of } \\
\text { Heat Treatment }\left({ }^{\circ} \mathbf{C}\right)\end{array}$ \\
\hline M1 & 0.2 & 600 & 0.2 & 0 & 50 \\
M2 & 0.2 & 1800 & 0.2 & 0 & 50 \\
M3 & 0.2 & 10,000 & 0.2 & 0 & 50 \\
M3/AGQDs-0.1 & 0.2 & 10,000 & 0.2 & 1000 & 50 \\
M3/AGQDs-0.2 & 0.2 & 10,000 & 0.2 & 2000 & 50 \\
M3/AGQDs-0.3 & 0.2 & 10,000 & 0.2 & 3000 & 50 \\
M3/AGQDs-0.4 & 0.2 & 10,000 & 0.2 & 4000 & 50 \\
\hline
\end{tabular}




\subsection{Characterization of AGQDs and NF Membranes}

The comprehensive characterizations of AGQDs by various methods, including Fourier transform infrared spectroscopy (FT-IR), transmission electron microscopy (TEM), atomic force microscopy (AFM), X-ray photoelectron spectroscopy (XPS), zeta potential, and X-ray diffraction (XRD) were based on our previous work [21]. The UV-Vis spectrophotometer (PerkinElmer Lambda 750 S, Massachusetts, USA) was used to obtain the UV-Vis absorption spectra of GQDs and AGQDs.

The functional groups and chemical composition of the membrane surfaces were analyzed by attenuated total reflectance-Fourier transform infrared spectroscopy (ATRFTIR, Bruker Vertex 70, Karlsruhe, Germany) and XPS (Physical Instruments Quantum 2000, Newark, DE, USA), respectively. The membrane surface hydrophilicity was measured using a contact angle goniometer (Beijing HARKE SPCAX3, China). The microscopic morphology of the prepared membranes was observed by SEM (LEO-1530, Oberkochen, Germany) operated at $10 \mathrm{kV}$.

\subsection{Photocatalytic Performance of GQDs and AGQDs}

The photocatalytic performance of GQDs and AGQDs on methyl blue (MB) was evaluated using a $75 \mathrm{~W}$ white LED lamp. Briefly, $1 \mathrm{mg}$ of GQDs or AGQDs powder was dissolved in a $20 \mathrm{ppm} \mathrm{MB}$ aqueous solution. The resulting solution was placed in the dark for $30 \mathrm{~min}$ to reach adsorption-desorption equilibrium. After that, the mixture was irradiated under the LED lamp for $30 \mathrm{~min}$, and the color change of the solution before and after irradiation was recorded. The absorption of $\mathrm{MB}$ solution before and after irradiation was measured by a UV-Vis spectrometer (SHIMADZU, UV-1780, Shimadzu, Japan), and the concentration was calculated by Lambert-Beer law. The photocatalytic abilities of GQDs or AGQDs were assessed in terms of the degradation degree of MB. The degradation degree (D) of MB is calculated by Equation (1):

$$
D(\%)=\left(1-\frac{C_{a}}{C_{b}}\right) \times 100 \%
$$

where $C_{b}$ and $C_{a}$ refer to the $\mathrm{MB}$ concentration before and after irradiation, respectively.

\subsection{Separation Performances of NF Membranes}

Water flux and rejection are critical parameters of NF membrane performance. Four different dyes (MB, CR, MO, and $\mathrm{RhB}$ ) were used to evaluate the overall dye rejection of fabricated NF membranes. A dead-end permeation cell ultrafiltration device (Millipore ${ }^{\circledR}$ Amicon, Billerica, MA, USA) was used to measure flux and rejection under the pressure of 2 bar at $25^{\circ} \mathrm{C}$.

The water flux is calculated by the following Equation (2):

$$
J=\frac{V}{A \Delta t}
$$

where $J$ is the water flux $\left(\mathrm{L} \cdot \mathrm{m}^{-2} \cdot \mathrm{h}^{-1}, \mathrm{LMH}\right), V$ is the permeate volume (L), $A$ represents the effective membrane area $\left(\mathrm{m}^{2}\right)$, and $\Delta t$ is the operation time (h).

The dye rejection $(\mathrm{R})$ is calculated by the following Equation (3):

$$
R(\%)=\left(1-\frac{C_{P}}{C_{c}}\right) \times 100 \%
$$

where $C_{p}$ and $C_{c}$ represent the dye concentration of the permeate and the concentrate, respectively. The UV spectrophotometer was used to determine the dye concentration based on the standard curve between the absorbance and the dye concentration. 


\subsection{Photocatalytic Self-Cleaning Performance of NF Membranes}

The photocatalytic self-cleaning performance of the tested membranes was evaluated in terms of membrane flux and dye rejection before and after light irradiation. The selfcleaning test process is illustrated in Figure 2. First, the tested membrane was installed and continuously filtered by MB solution for $8 \mathrm{~h}$, recording flux and MB rejection each $20 \mathrm{~min}$. Subsequently, the fouled membrane was washed with deionized water. After that, the washed membrane was irradiated under LED white light for $3 \mathrm{~h}$. Finally, the flux and rejection of the membrane was re-measured after light irradiation.

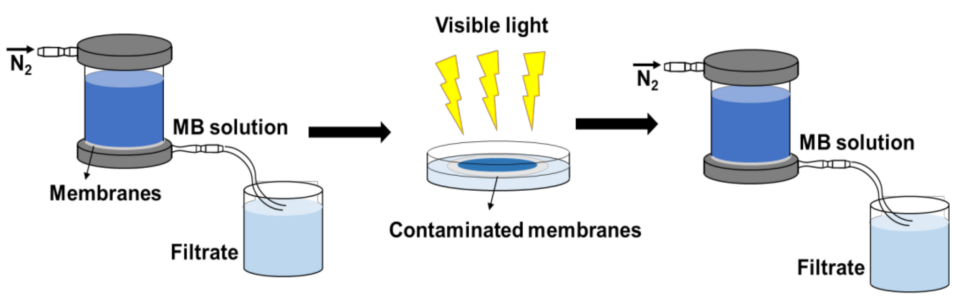

Figure 2. Self-cleaning test process of NF membrane.

\section{Results and Discussion}

\subsection{UV-Vis Diffuse Reflectance Characterization of GQDs and AGQDs}

The AGQDs synthesized by the bottom-up method have a dot-like structure with 4-9 nm (Figure 1). The comprehensive characterizations of AGQDs have been reported in our previous study [21]. The optical response of GQDs and AGQDs can be evaluated by UV-Vis diffuse reflectance spectroscopy. Compared with GQDs, the absorption peak of AGQDs shows a significant redshift, and the tail extends to the visible region. It indicates that AGQDs can absorb a part of visible light [15]. The bandgap energy can be obtained from the $(\alpha \mathrm{h} v)^{2}$ versus $\mathrm{h} v$ plots according to the Kubelka-Monk rule [15]. As shown in Figure 3B, the bandgap energy of AGQDs $(1.43 \mathrm{eV})$ is significantly lower than that of GQDs (2.58 eV). The lower bandgap energy of AGQDs reflects the stronger visible light response of AGQDs, which enhances the photocatalytic performance of AGQDs [11]. The edge-connected aspartic acid of AGQDs may introduce n-orbitals between $\pi$ and $\pi^{*}$ orbitals, which leads to the lower bandgap energy of AGQDs [18,22].
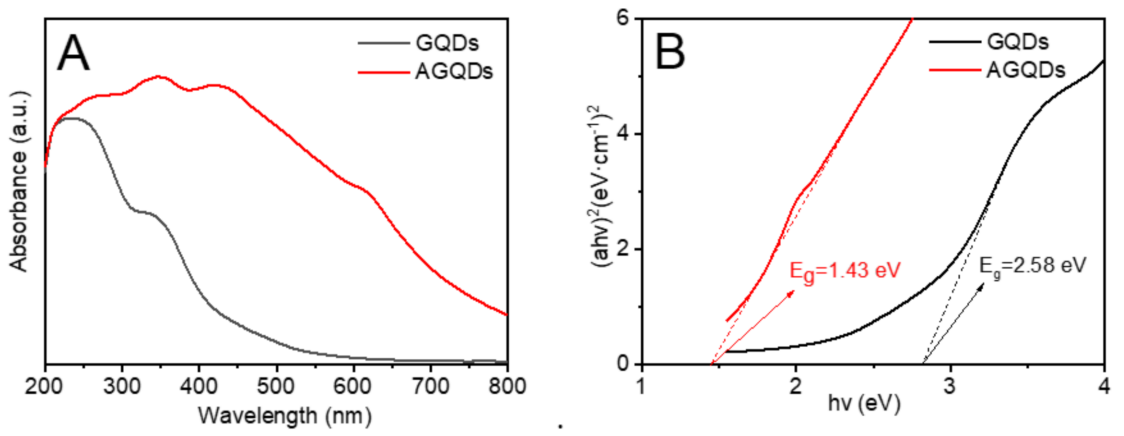

Figure 3. (A) UV-Vis spectra, (B) corresponding $(a h v)^{2}$ versus hv plots of GQDs and AGQDs.

\subsection{Characterization of the Prepared NF Membranes}

The surface morphologies of the fabricated NF membranes are shown in Figure 4. The PES substrate, M3 (PDA/PEI-10000), and M3/AGQDs-0.2 membranes show different morphological structures. Compared to the smooth surface of the PES substrate, the M3 membrane exhibits a rougher surface due to the disordered stacking of PDA and PEI during the co-deposition process [23,24]. The non-covalent interaction of PDA and PEI via co-deposition would produce an unstable PDA/PEI top layer [25]. It is reported that introducing reactive oxygen species (ROS) contributes to generating a more stable crosslinked structure of PDA, forming a tight selective layer $[20,26]$. As shown in Figure $4 \mathrm{C}$, the 
surface structure of the M3/AGQDs-0.2 membrane became smooth after the introduction of AGQDs, which may be due to the fact that AGQDs also produce $\mathrm{ROS}\left(\mathrm{O}_{2}{ }^{-}\right.$and $\left.\cdot \mathrm{OH}^{-}\right)$ after irradiation [15]. It suggests that AGQDs contributed to the chemical cross-linking of PDA and PEI to form a more compact, smooth, and stable membrane structure.

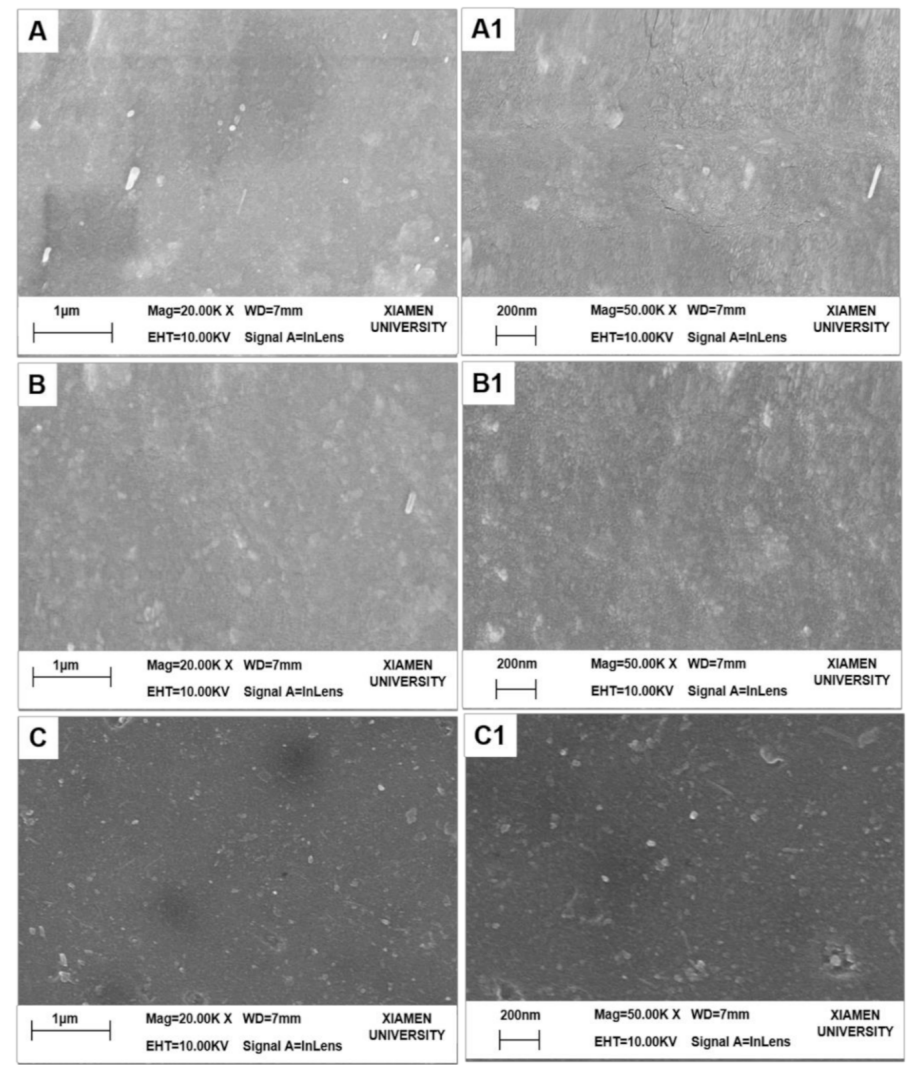

Figure 4. SEM images of UF and NF membranes (A-C: $20.00 \mathrm{~K} \times$, A1-C1: $50.00 \mathrm{~K} \times$ ): (A) PES substrate, (B) M3 membrane, (C) M3/AGQDs-0.2 NF membrane.

The chemical compositions of the membrane surfaces are analyzed by ATR-FTIR, as shown in Figure 5. The PES substrate exhibits a more pronounced characteristic peak around $1000-1100 \mathrm{~cm}^{-1}$, which is attributed to the stretching vibration of the $-\mathrm{SO}_{2}$ - group. In contrast, the intensities of the absorption peaks at $1000-1100 \mathrm{~cm}^{-1}$ for the $\mathrm{M} 3 \mathrm{membrane}$ and the M3/AGQDs-0.2 membrane are significantly weakened, which indicates that the M3/AGQDs-0.2 layer has been successfully deposited on the top of the PES substrate.

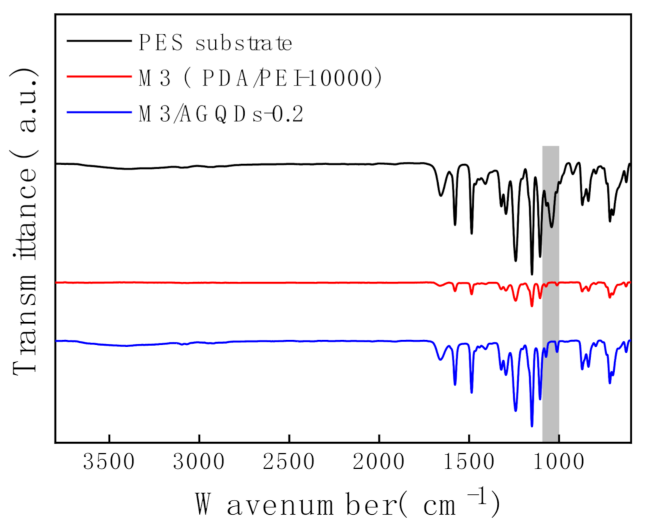

Figure 5. ATR-FTIR spectra of NF membranes. 
XPS was used to further analyze the chemical compositions and elemental contents of the membrane surfaces. According to Figure 6 and Table 2, the PES substrate presents the highest $S$ content owing to the existence of the $S$ element in the PES structure. Meanwhile, the M3 and the M3/AGQDs-0.2 membranes have the lower S element because of the formation of a thin selective layer on the PES substrate. This is consistent with the ATRFTIR results, demonstrating the deposition of selective layers on the PES substrate. It is found that the PES substrate contains a N element from its XPS spectra, which probably derives from the residual pore former such as polyvinylpyrrolidone containing a $\mathrm{N}$ element. In addition, according to Table 2, the M3/AGQDs- 0.2 membrane has the highest $\mathrm{N}$ content, which is attributed to the abundant $\mathrm{N}$ element from PEI and AGQDs [21]. The introduction of AGQDs might improve the degree of cross-linking between PDA and PEI during the co-deposition process, as deduced by the following mechanism analysis between PEI and PDA.

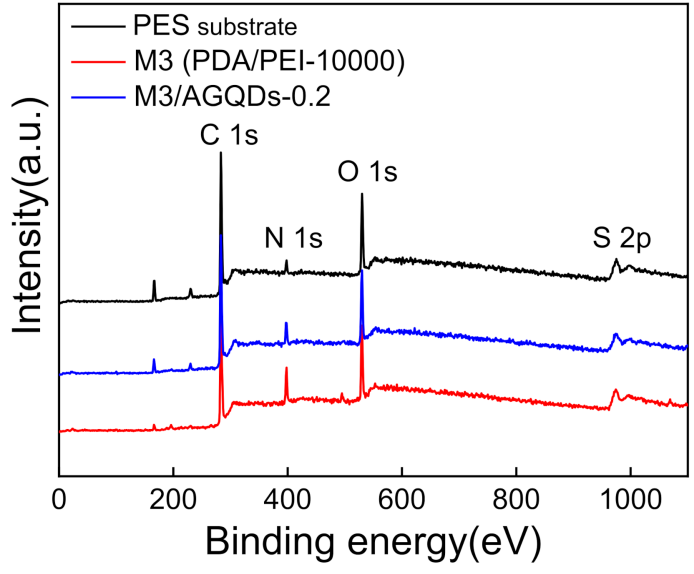

Figure 6. XPS full spectra of PES substrate and NF membranes.

Table 2. The chemical compositions of PES substrate and NF membranes by XPS.

\begin{tabular}{|c|c|c|c|c|c|c|}
\hline \multirow{2}{*}{ Membranes } & \multicolumn{4}{|c|}{ Atomic Concentration (\%) } & \multirow{2}{*}{${ }^{\text {a }} \mathrm{O} / \mathrm{N}$} & \multirow{2}{*}{${ }^{b} \mathrm{O} / \mathrm{C}$} \\
\hline & $\mathrm{C}$ & $\mathbf{N}$ & $\mathrm{O}$ & $\mathbf{S}$ & & \\
\hline PES substrate & 74.72 & 3.53 & 17.68 & 4.07 & 1.29 & 0.23 \\
\hline M3 (PDA/PEI-10000) & 71.85 & 7.92 & 17.66 & 2.57 & 1.30 & 0.24 \\
\hline M3/AGQDs-0.2 & 68.85 & 12.42 & 17.53 & 1.20 & 1.41 & 0.25 \\
\hline
\end{tabular}

${ }^{a} \mathrm{O} / \mathrm{N}$ : molar ratio of nitrogen to carbon in the selected layers.; ${ }^{b} \mathrm{O} / \mathrm{C}$ : molar ratio of oxygen to carbon in the selected layers.

The reaction mechanism of PDA and PEI is shown in Figure 7. It has been reported that the $\mathrm{pH}$ has a significant effect on the reaction between PDA and amines [27]. When the $\mathrm{pH}$ is less than 8.5 , it is difficult for the amino group to react with the catechol group inside PDA [28]. However, when $\mathrm{pH}$ is high above 8.5, the catechol group of PDA can be oxidized to form quinone groups, which can more easily react with the amino group via Michael addition or Schiff base reaction [29]. Moreover, the self-polymerization of PDA in alkaline solutions contributes to the adhesion of PDA to the PES substrate. In this study, the $\mathrm{pH}$ of the PDA solution was adjusted to 8.5 by tris-buffer solution. As a result, PEI was more readily chemically cross-linked with PDA, which improved the structural stability of the PDA/PEI composite.

The fitting curves were obtained by deconvolution of the raw intensity of XPS C1s for the PES substrate, M3 (PDA/PEI-10000), and M3/AGQDs-0.2 membranes (Figure 8A-C). The characteristic peak at $287.5 \mathrm{eV}$ for the M3 and M3/AGQDs- 0.2 membranes is attributed to $\mathrm{C}=\mathrm{O}$ in PDA due to the quinoid group within PDA [30]. Compared to the M3/AGQDs0.2 membrane, the $\mathrm{M} 3$ membrane shows a strong $\mathrm{C}=\mathrm{O}$ characteristic peak. It is attributed 
to the introduction of AGQDs generating ROS [31], which promotes the Schiff base reaction of PDA and reduces $\mathrm{C}=\mathrm{O}$ groups content. It is worth noting that AGQDs can be involved in cross-linking reactions being covalently attached to the PDA/PEI/AGQDs selective layer. The characteristic peak at $286 \mathrm{eV}$ is attributed to the $\mathrm{C}-\mathrm{O} / \mathrm{C}-\mathrm{N}$ group. The $\mathrm{C}-\mathrm{N}$ groups in the prepared membranes are mainly derived from the self-polymerization of PDA, chemical cross-linking of PDA/PEI, and additional introduction of AGQDs. The intensity of the $\mathrm{C}-\mathrm{O} / \mathrm{C}-\mathrm{N}$ characteristic peak of the M3/AGQDs- 0.2 membrane is stronger than that of the M3 membrane. On the one hand, the AGQDs in the PDA/PEI/AGQDs selective layer introduce an extra $\mathrm{N}$ element. On the other hand, the $-\mathrm{NH}_{2}$ from AGQDs can participate in the cross-linking reaction, increasing the $\mathrm{C}-\mathrm{N}$ content. The results further demonstrate that AGQDs have a significant effect on the chemical cross-linking of PDA and PEI.

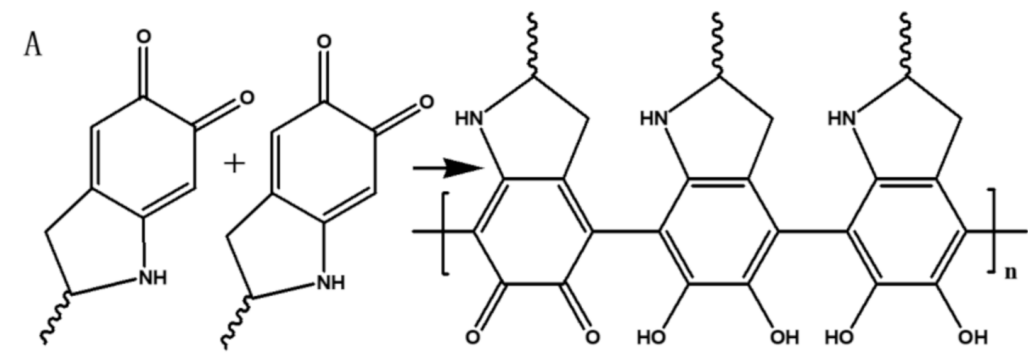

B<smiles>CCCNC1=C2N[C@H](C)CC2=CC(=O)C1=O</smiles><smiles>CCCC(C)N=C1C=C2NC(C)CC2=CC1=O</smiles>

Figure 7. Reaction mechanisms between PDA and PEI: (A) self-polymerization of PDA, (B) Michael addition and Schiff base reaction of PDA and PEI.

The water contact angle (WCA) of the NF membrane is closely related to the roughness and hydrophilicity of the membrane surface, as shown in Figure 9. It was found that the introduction of the PDA/PEI selective layer significantly reduced the hydrophilicity of the membrane surface, with a decrease in WCA from $61.5^{\circ}$ to $43.0^{\circ}$. The AFM results show that the PES substrate has a similar surface roughness to the M3 membrane. Therefore, the remarkably decreasing WCA of the M3 membrane benefits from the excellent hydrophilicity of PDA [32]. The M3/AGQDs- 0.2 membrane demonstrates the lowest WCA (36.5 ), which is caused by the synergistic effects of the smooth membrane surface and the inherent hydrophilic properties of AGQDs and PDA. 

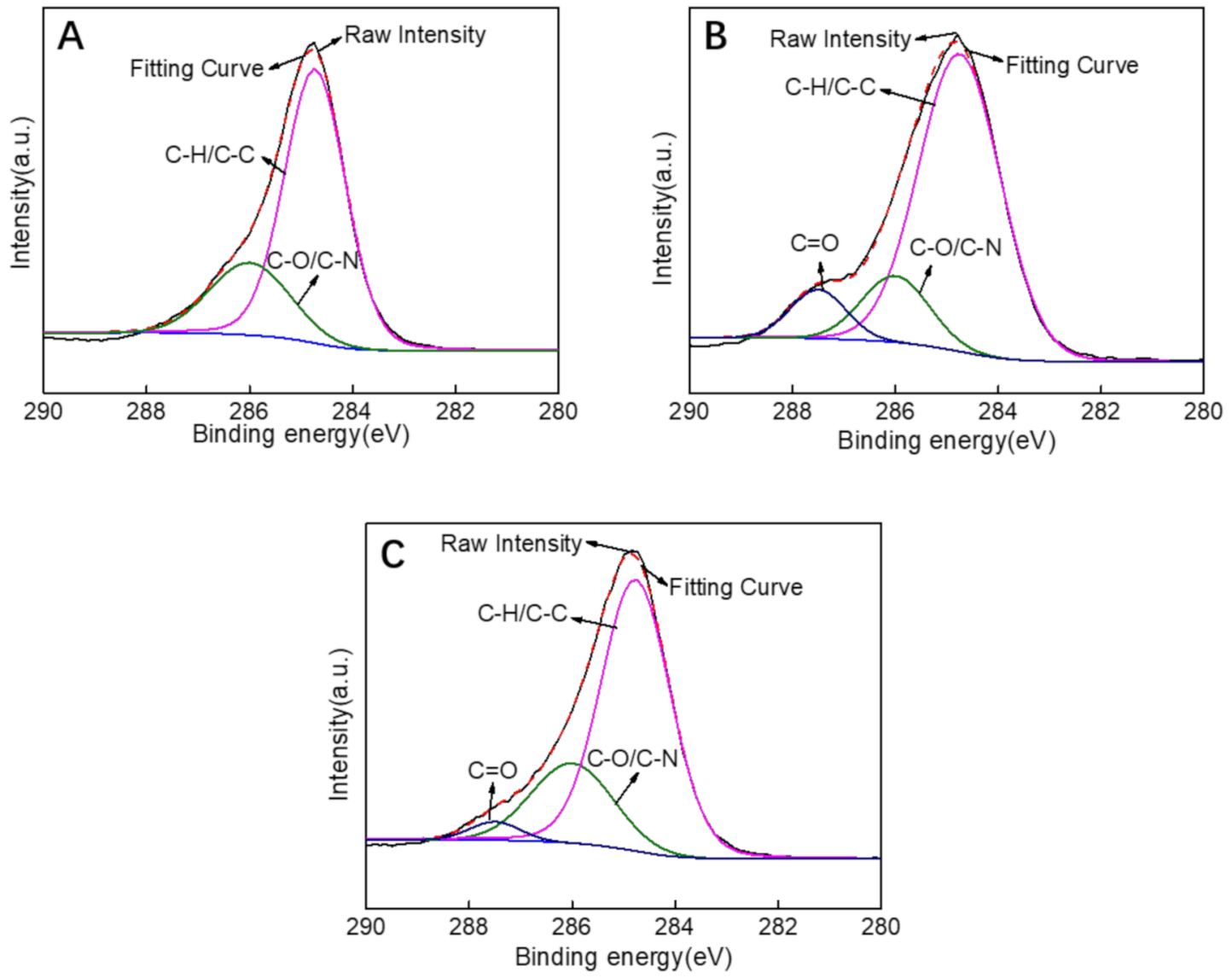

Figure 8. XPS C1s spectrum of PES substrate (A), M3 (PDA/PEI-10000) membrane (B), M3/AGQDs0.2 membrane $(\mathbf{C})$.

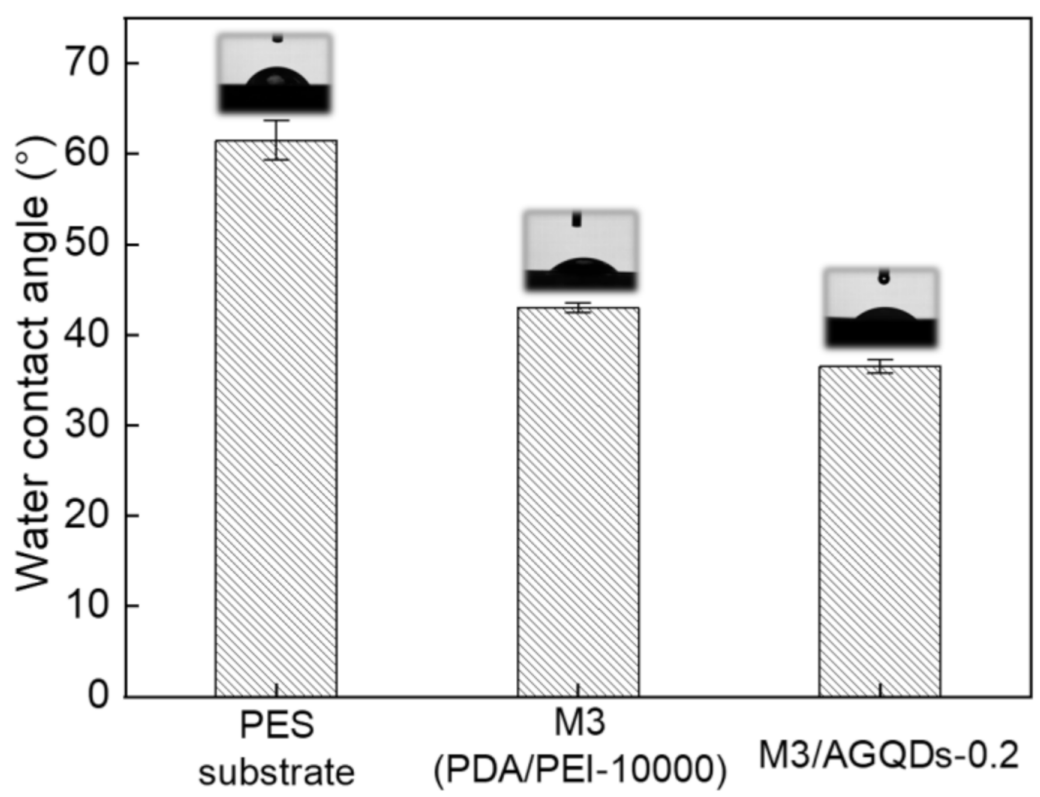

Figure 9. The water contact angle of the prepared membranes.

\subsection{Separation Performance of the Fabricated Membranes}

The PEI molecular weight for constructing the PDA/PEI membranes performance was optimized from three kinds of PEI molecular weights $(600,1800$, and $10,000 \mathrm{Da})[33,34]$. According to Figure 10, the water flux of the prepared membrane is inversely proportional 
to the PEI molecular weight, owing to the higher molecular weight PEI cross-linking with the PDA to form a denser selective layer. Correspondingly, the increased molecular weight of PEI contributes to the improved dye rejection of the PDA/PEI membranes. It is found that PEI with a molecular weight of 10,000 Da exhibits a high rejection with the reasonable flux, which is regarded as the optimal molecular weight of PEI cross-linking reagent in this study.

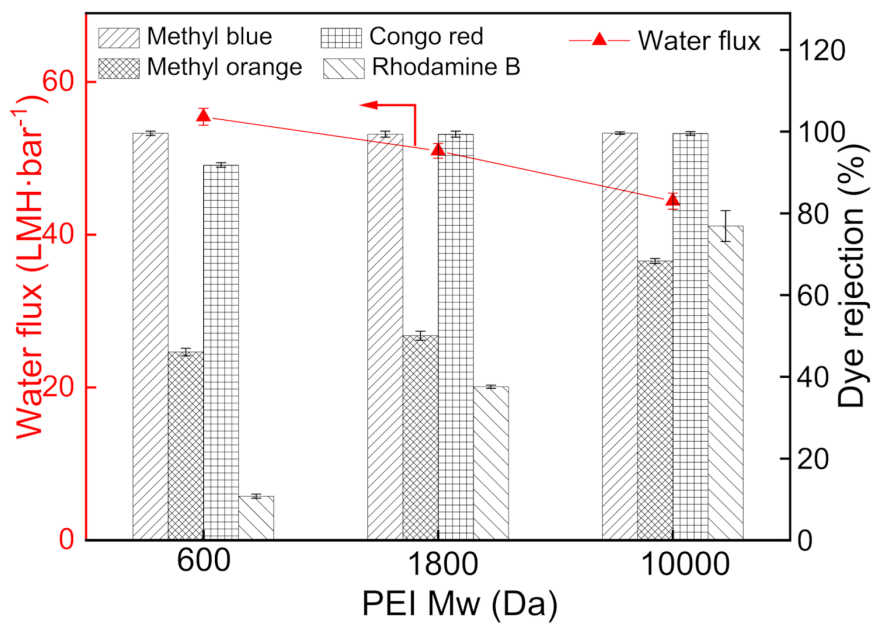

Figure 10. Influence of PEI molecular weight on the separation performance of PDA/PEI membranes (testing conditions: 2 bar, $25^{\circ} \mathrm{C}$ ).

The influence of the AGQDs concentrations on the separation performance of the PDA/PEI/AGQDs membranes is shown in Figure 11. With the increase in AGQDs concentration, the water flux shows a trend of first increasing and then decreasing. Compared to the M3 (PDA/PEI-10000) membrane, introducing a suitable amount of AGQDs contributes to optimizing the membrane microstructures and properties, which improves the water flux without reducing dye rejection. On the one hand, AGQDs can facilitate the cross-linking reaction between PDA and PEI. On the other hand, the presence of AGQDs may reduce the membrane pore blockings caused by PDA self-polymerization [35]. However, while AGQDs content increases from 2000 to 4000 ppm, the water flux of the PDA/PEI/AGQDs membranes decreases from 55.5 to $44.2 \mathrm{LMH} \cdot \mathrm{bar}^{-1}$. The water flux reduction is excessive, since AGQDs may block the pore channels and increase the filtration resistance. Therefore, considering the permeability and rejection of NF membranes, the optimum concentration of AGQDs is 2000 ppm to construct the PDA/PEI/AGQDs membrane.
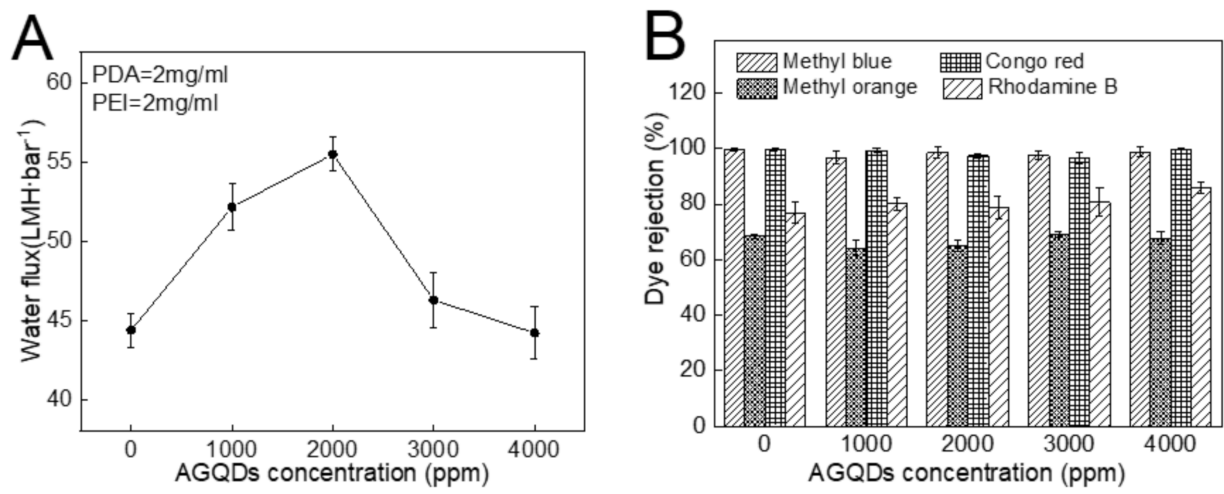

Figure 11. Water flux (A) and dye rejections (B) of PDA/PEI/AGQDs membranes as a function of AGQDs concentration. 
Four kinds of dyes (MB, CR, MO, and $\mathrm{RhB})$ with different molecular weights and charges are used to systematically investigate the separation performance of the PDA/PEI/ AGQDs membranes [13]. The molecular weights and charge properties of different dyes are listed in Table 3, and the dye rejections of the M3/AGQDs membranes are shown in Figure 11B. The M3/AGQDs membranes present almost 100\% rejection toward MB and $\mathrm{CR}$, primarily resulting from the size exclusion effect between the PDA/PEI/AGQDs membranes and dyes with large molecular weight (MB and $\mathrm{CR}$ ). The rejection of four dyes follows the order of $\mathrm{MB} \approx \mathrm{CR}>\mathrm{RhB}>\mathrm{MO}$, which is similar to the molecular weight order of four dyes. It indicates that the size exclusion effect plays a critical role in dye rejection.

Table 3. Molecular weight and charged property of different dyes.

\begin{tabular}{ccccc}
\hline Dyes & Methyl Blue & Methyl Orange & Congo Red & Rhodamine B \\
\hline $\begin{array}{c}\text { Molecular weight } \\
{\left[\mathrm{g} \cdot \mathrm{mol}^{-1} \text { ] }\right.}\end{array}$ & 799.80 & 327.33 & 696.68 & 479.01 \\
Charge under $\mathrm{pH}=7.0$ & positive & negative & negative & positive \\
\hline
\end{tabular}

\subsection{Self-Cleaning Performance of the Fabricated Membranes}

The anti-fouling performance is crucial for the successful application of NF membranes [36]. Severe membrane fouling will significantly increase the cost of water treatment [37]. The engineered NF membrane endowed with photocatalytic self-cleaning property is expected to improve the anti-fouling performance [38]. In this study, the photocatalytic self-cleaning performance of the M3/AGQDs- 0.2 membrane was evaluated by $8 \mathrm{~h}$ continuous filtration.

$\mathrm{MB}$ has a large molecular weight and a high rejection rate, which results in its easy enrichment on the membrane surface. Thus, MB was selected as a mode foulant to evaluate the self-cleaning performance of the selected membranes (the M3 and M3/AGQDs-0.2 membranes). Figure 12 shows the normalized flux and $\mathrm{MB}$ rejection before and after light irradiation. According to Figure 12A, the normalized fluxes of the M3 and M3/AGQDs-0.2 membranes gradually decreased with the operation time. On the one hand, the enrichment of retained $\mathrm{MB}$ molecules on the membrane surface may cause concentration polarization [39]. On the other hand, MB could block the membrane pores, which increased the mass transfer resistance of the membrane filtration process [40]. As a result, the synergistic effect leads to a significant flux reduction. The water flux could be partially restored after water washing and light irradiation. Most importantly, the introduction of AGQDs imparts photocatalytic degradation ability to the M3/AGQDs- 0.2 membrane. The M3/AGQDs- 0.2 membrane shows a significantly higher flux recovery rate than the $\mathrm{M} 3 \mathrm{membrane}(83 \% \mathrm{vs}$. $69 \%$ ) owing to the photocatalytic degradation of MB by the M3/AGQDs- 0.2 membrane. In contrast, the M3 membrane only removed a limited number of foulants from the membrane surface by water washing, resulting in a lower flux recovery rate.
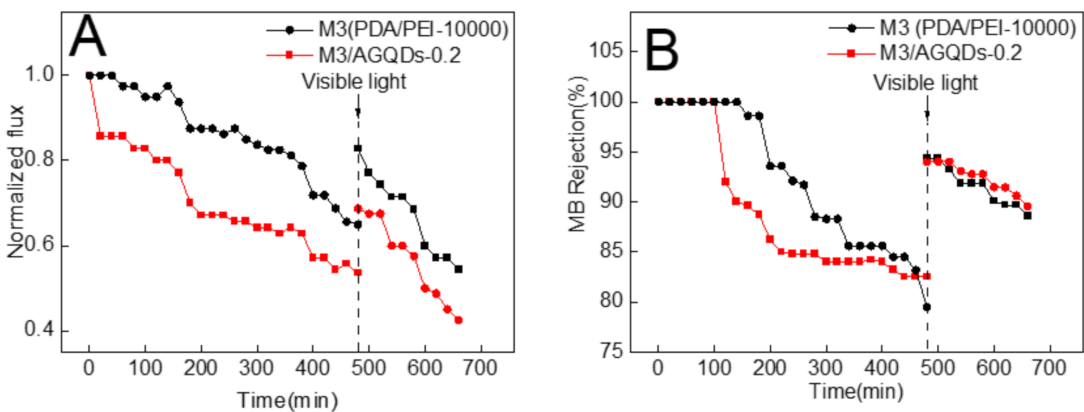

Figure 12. Photocatalytic self-cleaning properties of the prepared membranes: (A) normalized water fluxes and (B) MB rejection before and after irradiation. 
The MB rejection of the NF membranes mainly depends on by the size sieving effect and the Donnan effect. As shown in Figure 12B, in the early filtration stages, the tested NF membranes have a high $\mathrm{MB}$ rejection under the combined influences. With more and more MB enrichment on the membrane surface, the Donnan effect gradually weakens, which results in a lower rejection. After water washing and light irradiation, the MB rejection of the M3/AGQDs-0.2 membrane recovers to the initial level.

Figure 13A shows the color variation of the membrane surface before and after light irradiation. It is obvious that the M3/ AGQDs- 0.2 membrane exhibits better photocatalytic self-cleaning performance than the M3 (PDA/PEI-10000) membrane. The blue color of MB almost disappears from the M3/AGQDs-0.2 membrane surface after light irradiation, while the blue color remains on the surface of the PDA/PEI membrane. After light irradiation, ATR-FTIR was used to further measure the residual MB on the membrane surface. Figure 13 demonstrates the FTIR spectra of the MB powder, M3, and M3/AGQDs-0.2 membranes surface after irradiation, respectively. The aromatic skeleton absorption peak of $\mathrm{MB}$ is found at $1514-1572 \mathrm{~cm}^{-1}$. The absorption peaks at $1172-1118 \mathrm{~cm}^{-1}$ are attributed to the symmetric and asymmetric stretching vibrations of the sulfonic acid group $\mathrm{S}=\mathrm{O}$ in $\mathrm{MB}$ [41]. According to Figure 13B, the M3/AGQDs-0.2 membrane exhibits a remarkably weaker characteristic peak of $\mathrm{MB}$ than the $\mathrm{M} 3$ membrane. This result further indicates that the M3/AGQDs-0.2 membrane demonstrates excellent photocatalytic degradation toward MB with the help of AGQDs.
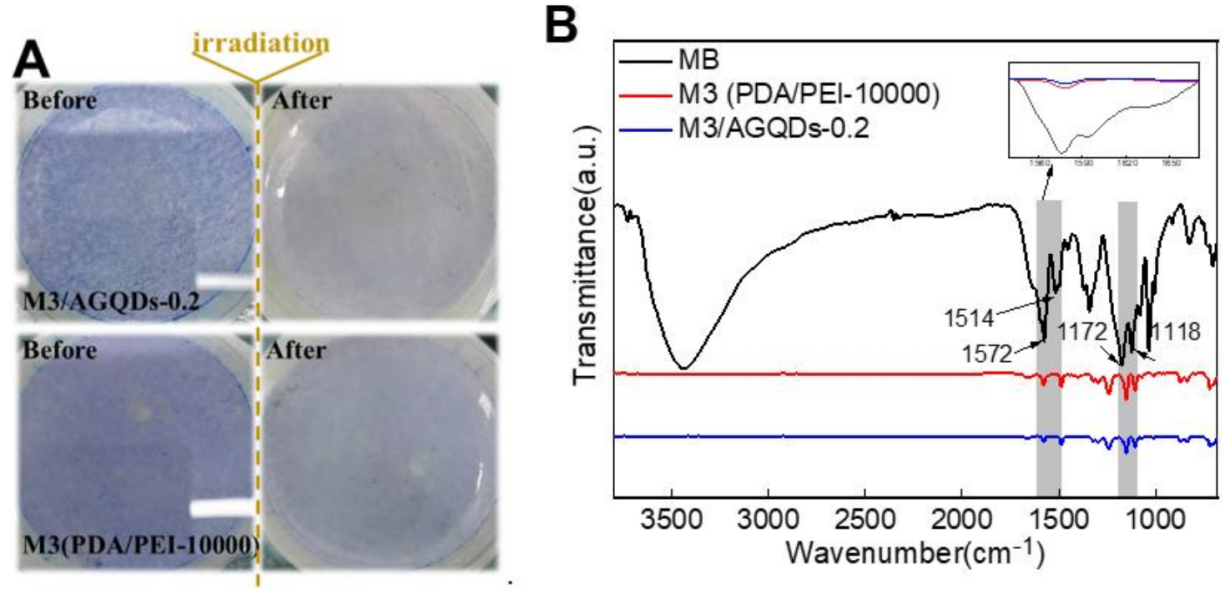

Figure 13. The surface of NF membranes before and after visible light irradiation (A) and FT—IR spectrum of methyl blue and NF membranes (B).

The photocatalytic degradation mechanism of MB by AGQDs is explored by comparison with GQDs. According to Figure 14A, both AGQDs and GQDs exhibit photocatalytic abilities for MB. Under visible light conditions, the valence electrons $\left(\mathrm{e}^{-}\right)$in the photocatalyst can be excited to the conduction band (CB) and generate ROS (such as $\mathrm{O}_{2}{ }^{-}$and $\cdot \mathrm{OH}^{-}$) clusters in the aqueous environment. ROS can combine with $\mathrm{MB}$ and carry out redox reactions to produce $\mathrm{CO}_{2}, \mathrm{H}_{2} \mathrm{O}$, and degradation products $[15,42,43]$.

According to Figure 14B, the photocatalytic degradation of MB by AGQDs was significantly better than that of GQDs. Compared with GQDs, the concentration of MB solution with AGQDs is significantly decreased after light irradiation (MB degradation rate $88 \%$ vs. 51\%), which is consistent with the color change results in Figure 14A. According to the results in Figure 3B, AGQDs exhibit a lower bandgap energy than GQDs, indicating that AGQDs have a better visible light absorption capacity [44]. The low bandgap energy allows AGQDs to produce more photogenerated charge carriers $\left(\mathrm{e}^{-}\right.$and $\left.\mathrm{h}^{+}\right)$in visible light, thereby facilitating MB degradation. In addition, as a photosensitizer, MB turns into an unstable excited state under visible light irradiation. The oxygen atoms with strong oxidation properties are generated in the excited state, which leads to the spontaneous degradation process. In the presence of AGQDs, the $\mathrm{e}^{-}$generated by MB excitation can 
be stored in AGQDs, which may hinder the complexation between $\mathrm{e}^{-}$and $\mathrm{h}^{+}$and hence be more favorable for MB degradation. Additionally, Table 4 indicates that the optimal PDA/PEI/AGQDs membrane in this study achieves higher water flux and dye rejection than other NF membranes in the literature. Therefore, the co-deposition method can be an effective strategy for constructing high-performance dye separation membranes.
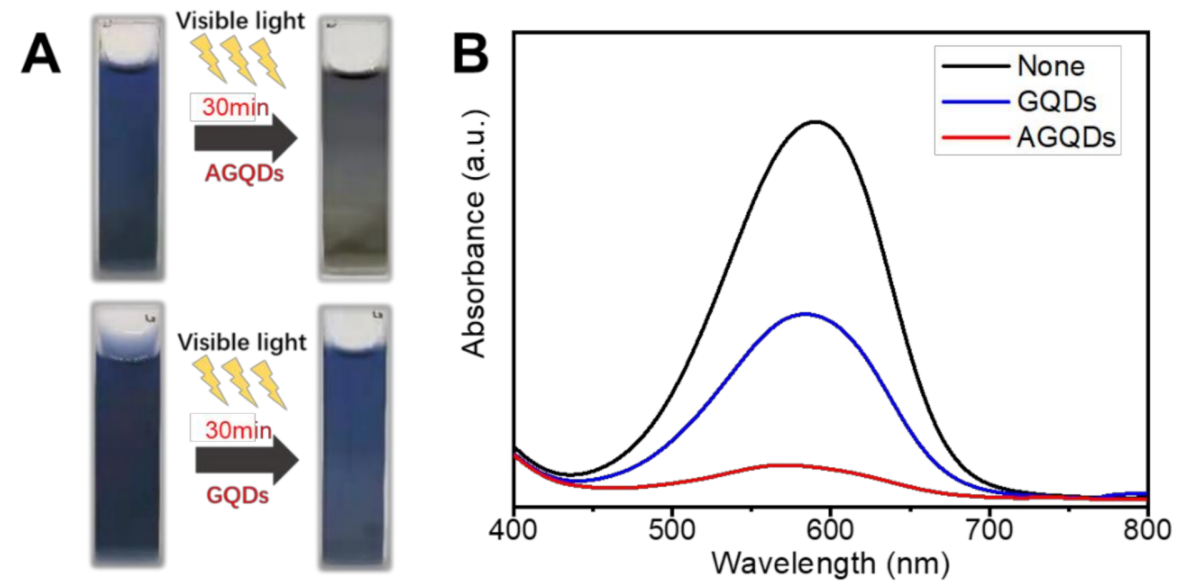

Figure 14. Photocatalytic degradation of MB by AGQDs and GQDs (A), UV-Visible spectrum of MB after irradiation (B).

Table 4. Comparisons of water permeability and MB rejection between this study and literatures.

\begin{tabular}{ccccc}
\hline Membrane Type & $\begin{array}{c}\text { Permeability } \\
\text { (LMH/bar) }\end{array}$ & Testing Conditions & MB Rejection (\%) & Reference \\
\hline CuTz-1-GO/PAN & 40.2 & $500 \mathrm{ppm}, 0.4 \mathrm{Mpa}, 25^{\circ} \mathrm{C}$ & 94.9 & {$[45]$} \\
TA-Fe $3+$ PAN & 40.9 & $35 \mu \mathrm{mol} / \mathrm{L}, 0.2 \mathrm{Mpa}, 25^{\circ} \mathrm{C}$ & 93.9 & {$[46]$} \\
GO-Ca-SA/PVDF & 38.9 & $20 \mathrm{ppm}, 0.12 \mathrm{Mpa}, 25^{\circ} \mathrm{C}$ & $99+$ & {$[47]$} \\
MXene-PEI-TMC/PAN & 20.9 & $200 \mathrm{ppm}, 0.4 \mathrm{Mpa}, 25^{\circ} \mathrm{C}$ & 98.84 & {$[48]$} \\
TiO2-HMDI/PES & 26 & $35 \mu \mathrm{mol} / \mathrm{L}, 0.2 \mathrm{Mpa}, 25^{\circ} \mathrm{C}$ & 99.1 & {$[49]$} \\
PIP-CS-TMC/PES & $49.6-128.8$ & $100 \mathrm{ppm}, 0.5 \mathrm{Mpa}, 25^{\circ} \mathrm{C}$ & $99+$ & {$[50]$} \\
ZIF-8\&PEI/PAN & 33.0 & $100 \mathrm{ppm}, 0.4 \mathrm{Mpa}, 20^{\circ} \mathrm{C}$ & 99.6 & {$[51]$} \\
AGQDs-PDA-PEI/PES & 55.5 & $20 \mathrm{ppm}, 0.2 \mathrm{Mpa}, 25^{\circ} \mathrm{C}$ & 99.7 & This work \\
\hline
\end{tabular}

\section{Conclusions}

In this study, the PDA/PEI/AGQDs NF membrane with self-cleaning performance was constructed by the co-deposition method. The results indicate that the introduction of photocatalytic AGQDs into the selective layer contributes to improving the separation performance and imparts photocatalytic self-cleaning performance to NF membranes. The PDA/PEI/AGQDs membrane fabricated by suitable PEI molecular weight (10,000 Da) and AGQDs concentration (2000 ppm) demonstrated the highest water permeability of $55.5 \mathrm{LMH} \cdot \mathrm{bar}^{-1}$ while maintaining high dye rejection $(99.7 \pm 0.3 \%$ for $\mathrm{MB})$. This is achieved by the formation of the dense and hydrophilic PDA/PEI/AGQDs selective layer. Moreover, the M3/AGQDs-0.2 membrane demonstrates excellent self-cleaning performance due to the low bandgap energy of AGQDs. The water flux recovery of the M3/AGQDs-0.2 membrane is significantly higher than that of the M3 (PDA/PEI-10000) membrane after light irradiation. Generally, through in-depth analysis of the degradation MB mechanism of AGQDs, the excellent photocatalytic degradation performance of AGQDs is well confirmed, which provides a new approach to construct self-cleaning NF membranes. 


\begin{abstract}
Author Contributions: Conceptualization, Q.X. and C.W.; Data curation, T.Y. and C.W.; Formal analysis, T.Y., C.W. and Q.X.; Funding acquisition, Q.X.; Investigation, T.Y., C.W., Z.C., M.Z. and H.G.; Methodology, Q.X. and C.W.; Resources, Z.H.; Supervision, Q.X. and W.S.; Writing一original draft, T.Y. and C.W.; Writing - review \& editing, Q.X. All authors have read and agreed to the published version of the manuscript.
\end{abstract}

Funding: This work is supported by the Science \& Technology Planning Project of Fujian Province (No. 2019H0049), the Scientific Research Foundation of Third Institute of Oceanography, MNR (No. 2019012), and Xiamen Ocean Research and Development Institute (No. K200103).

Data Availability Statement: The data presented in this study are available on request from the corresponding author.

Conflicts of Interest: The authors declare no conflict of interest. The funders had no role in the design of the study; in the collection, analyses, or interpretation of data; in the writing of the manuscript, or in the decision to publish the results.

\title{
References
}

1. Wenderich, K.; Mul, G. Methods, Mechanism, and Applications of Photodeposition in Photocatalysis: A Review. Chem. Rev. 2016, 116, 14587-14619. [CrossRef]

2. Xu, C.; Anusuyadevi, P.R.; Aymonier, C.; Luque, R.; Marre, S. Nanostructured materials for photocatalysis. Chem. Soc. Rev. 2019, 48, 3868-3902. [CrossRef]

3. Li, Y.; He, S.; Zhou, Z.; Zhou, S.; Huang, S.; Fane, A.G.; Zheng, C.; Zhang, Y.; Zhao, S. Carboxylated Nanodiamond-Enhanced Photocatalytic Membranes with Improved Antifouling and Self-Cleaning Properties. Ind. Eng. Chem. Res. 2020, 59, 3538-3549. [CrossRef]

4. $\quad$ Liu, Y.; Su, Y.; Guan, J.; Cao, J.; Zhang, R.; He, M.; Gao, K.; Zhou, L.; Jiang, Z. 2D Heterostructure Membranes with Sunlight-Driven Self-Cleaning Ability for Highly Efficient Oil-Water Separation. Adv. Funct. Mater. 2018, 28, 1706545. [CrossRef]

5. Nyamutswa, L.T.; Zhu, B.; Collins, S.F.; Navaratna, D.; Duke, M.C. Light conducting photocatalytic membrane for chemical-free fouling control in water treatment. J. Membr. Sci. 2020, 604, 118018. [CrossRef]

6. Zhu, R.; Diaz, A.J.; Shen, Y.; Qi, F.; Chang, X.; Durkin, D.P.; Sun, Y.; Solares, S.D.; Shuai, D. Mechanism of humic acid fouling in a photocatalytic membrane system. J. Membr. Sci. 2018, 563, 531-540. [CrossRef]

7. Nurunnabi, M.; Khatun, Z.; Nafiujjaman, M.; Lee, D.-G.; Lee, Y.-K. Surface Coating of Graphene Quantum Dots Using MusselInspired Polydopamine for Biomedical Optical Imaging. ACS Appl. Mater. Interfaces 2013, 5, 8246-8253. [CrossRef] [PubMed]

8. Lv, Y.; Du, Y.; Chen, Z.-X.; Qiu, W.-Z.; Xu, Z.-K. Nanocomposite membranes of polydopamine/electropositive nanoparticles/polyethyleneimine for nanofiltration. J. Membr. Sci. 2018, 545, 99-106. [CrossRef]

9. Feng, K.; Hou, L.; Tang, B.; Wu, P. A self-protected self-cleaning ultrafiltration membrane by using polydopamine as a free-radical scavenger. J. Membr. Sci. 2015, 490, 120-128. [CrossRef]

10. Wu, H.; Liu, Y.; Mao, L.; Jiang, C.; Ang, J.; Lu, X. Doping polysulfone ultrafiltration membrane with TiO2-PDA nanohybrid for simultaneous self-cleaning and self-protection. J. Membr. Sci. 2017, 532, 20-29. [CrossRef]

11. Shao, D.-D.; Yang, W.-J.; Xiao, H.-F.; Wang, Z.-Y.; Zhou, C.; Cao, X.-L.; Sun, S.-P. Self-Cleaning Nanofiltration Membranes by Coordinated Regulation of Carbon Quantum Dots and Polydopamine. ACS Appl. Mater. Interfaces 2020, 12, 580-590. [CrossRef] [PubMed]

12. Wang, T.; Qiblawey, H.; Sivaniah, E.; Mohammadian, A. Novel methodology for facile fabrication of nanofiltration membranes based on nucleophilic nature of polydopamine. J. Membr. Sci. 2016, 511, 65-75. [CrossRef]

13. Xu, Y.; Li, Z.; Su, K.; Fan, T.; Cao, L. Mussel-inspired modification of PPS membrane to separate and remove the dyes from the wastewater. Chem. Eng. J. 2018, 341, 371-382. [CrossRef]

14. Lv, Y.; Zhang, C.; He, A.; Yang, S.-J.; Wu, G.-P.; Darling, S.B.; Xu, Z.-K. Photocatalytic Nanofiltration Membranes with Self-Cleaning Property for Wastewater Treatment. Adv. Funct. Mater. 2017, 27, 1700251. [CrossRef]

15. Ibarbia, A.; Grande, H.J.; Ruiz, V. On the Factors behind the Photocatalytic Activity of Graphene Quantum Dots for Organic Dye Degradation. Part. Part. Syst. Charact. 2020, 37, 2000061. [CrossRef]

16. Liu, M.L.; Chen, B.B.; Li, C.M.; Huang, C.Z. Carbon dots: Synthesis, formation mechanism, fluorescence origin and sensing applications. Green Chem. 2019, 21, 449-471. [CrossRef]

17. Wang, Y.F.; Hu, A.G. Carbon quantum dots: Synthesis, properties and applications. J. Mater. Chem. C 2014, 2, 6921-6939. [CrossRef]

18. Li, L.; Wu, G.; Yang, G.; Peng, J.; Zhao, J.; Zhu, J.-J. Focusing on luminescent graphene quantum dots: Current status and future perspectives. Nanoscale 2013, 5, 4015-4039. [CrossRef]

19. Qian, Z.S.; Ma, J.J.; Shan, X.Y.; Shao, L.X.; Zhou, J.; Chen, J.R.; Feng, H. Surface functionalization of graphene quantum dots with small organic molecules from photoluminescence modulation to bioimaging applications: An experimental and theoretical investigation. RSC Adv. 2013, 3, 14571-14579. [CrossRef] 
20. Li, J.; Yuan, S.; Wang, J.; Zhu, J.; Shen, J.; van der Bruggen, B. Mussel-inspired modification of ion exchange membrane for monovalent separation. J. Membr. Sci. 2018, 553, 139-150. [CrossRef]

21. Wu, C.; Xie, Q.; Hong, Z.; Shen, L.; Yu, T.; Guo, H.; Xiong, Y.; Zhang, G.; Lu, Y.; Shao, W. Thin-film nanocomposite nanofiltration membrane with enhanced desalination and antifouling performance via incorporating L-aspartic acid functionalized graphene quantum dots. Desalination 2021, 498, 13. [CrossRef]

22. Yan, Y.B.; Chen, J.; Li, N.; Tian, J.Q.; Li, K.X.; Jiang, J.Z.; Liu, J.Y.; Tian, Q.H.; Chen, P. Systematic Bandgap Engineering of Graphene Quantum Dots and Applications for Photocatalytic Water Splitting and $\mathrm{CO}_{2}$ Reduction. ACS Nano 2018, 12, 3523-3532. [CrossRef] [PubMed]

23. Ji, Y.-L.; Ang, M.B.M.Y.; Huang, S.-H.; Lu, J.-Y.; Tsai, S.-J.; De Guzman, M.R.; Tsai, H.-A.; Hu, C.-C.; Lee, K.-R.; Lai, J.-Y. Performance evaluation of nanofiltration polyamide membranes based from 3,3'-diaminobenzidine. Sep. Purif. Technol. 2019, 211, 170-178. [CrossRef]

24. Lv, Y.; Yang, H.-C.; Liang, H.-Q.; Wan, L.-S.; Xu, Z.-K. Novel nanofiltration membrane with ultrathin zirconia film as selective layer. J. Membr. Sci. 2016, 500, 265-271. [CrossRef]

25. Liu, M.-L.; Guo, J.-L.; Japip, S.; Jia, T.-Z.; Shao, D.-D.; Zhang, S.; Li, W.-J.; Wang, J.; Cao, X.-L.; Sun, S.-P. One-step enhancement of solvent transport, stability and photocatalytic properties of graphene oxide/polyimide membranes with multifunctional cross-linkers. J. Mater. Chem. A 2019, 7, 3170-3178. [CrossRef]

26. Wang, J.; Zhu, J.; Tsehaye, M.T.; Li, J.; Dong, G.; Yuan, S.; Li, X.; Zhang, Y.; Liu, J.; van der Bruggen, B. High flux electroneutral loose nanofiltration membranes based on rapid deposition of polydopamine/polyethyleneimine. J. Mater. Chem. A 2017, 5, 14847-14857. [CrossRef]

27. Tian, Y.; Cao, Y.; Wang, Y.; Yang, W.; Feng, J. Realizing Ultrahigh Modulus and High Strength of Macroscopic Graphene Oxide Papers Through Crosslinking of Mussel-Inspired Polymers. Adv. Mater. 2013, 25, 2980-2983. [CrossRef]

28. Lee, H.; Dellatore, S.M.; Miller, W.M.; Messersmith, P.B. Mussel-inspired surface chemistry for multifunctional coatings. Science 2007, 318, 426-430. [CrossRef]

29. Lee, H.; Lee, Y.; Statz, A.R.; Rho, J.; Park, T.G.; Messersmith, P.B. Substrate-independent layer-by-layer assembly by using mussel-adhesive-inspired polymers. Adv. Mater. 2008, 20, 1619-1623. [CrossRef]

30. Li, X.; Liu, C.; Yin, W.; Chong, T.H.; Wang, R. Design and development of layer-by-layer based low-pressure antifouling nanofiltration membrane used for water reclamation. J. Membr. Sci. 2019, 584, 309-323. [CrossRef]

31. Ye, W.; Liu, H.; Lin, F.; Lin, J.; Zhao, S.; Yang, S.; Hou, J.; Zhou, S.; van der Bruggen, B. High-flux nanofiltration membranes tailored by bio-inspired co-deposition of hydrophilic g-C3N4 nanosheets for enhanced selectivity towards organics and salts. Environ. Sci.-Nano 2019, 6, 2958-2967. [CrossRef]

32. Wu, M.; Yuan, J.; Wu, H.; Su, Y.; Yang, H.; You, X.; Zhang, R.; He, X.; Khan, N.A.; Kasher, R.; et al. Ultrathin nanofiltration membrane with polydopamine-covalent organic framework interlayer for enhanced permeability and structural stability. $J$. Membr. Sci. 2019, 576, 131-141. [CrossRef]

33. Qiu, W.-Z.; Yang, H.-C.; Xu, Z.-K. Dopamine-assisted co-deposition: An emerging and promising strategy for surface modification. Adv. Colloid Interface Sci. 2018, 256, 111-125. [CrossRef] [PubMed]

34. Zhu, J.; Yuan, S.; Uliana, A.; Hou, J.; Li, J.; Li, X.; Tian, M.; Chen, Y.; Volodin, A.; Van der Bruggen, B. High-flux thin film composite membranes for nanofiltration mediated by a rapid co-deposition of polydopamine/piperazine. J. Membr. Sci. 2018, 554, 97-108. [CrossRef]

35. Choi, H.-G.; Shah, A.A.; Nam, S.-E.; Park, Y.-I.; Park, H. Thin-film composite membranes comprising ultrathin hydrophilic polydopamine interlayer with graphene oxide for forward osmosis. Desalination 2019, 449, 41-49. [CrossRef]

36. Zhang, R.; Liu, Y.; He, M.; Su, Y.; Zhao, X.; Elimelech, M.; Jiang, Z. Antifouling membranes for sustainable water purification: Strategies and mechanisms. Chem. Soc. Rev. 2016, 45, 5888-5924. [CrossRef]

37. Werber, J.R.; Osuji, C.O.; Elimelech, M. Materials for next-generation desalination and water purification membranes. Nature Rev. Mater. 2016, 1, 16018. [CrossRef]

38. Geng, Z.; Wang, X.; Jiang, H.; Zhang, L.; Chen, Z.; Feng, Y.; Geng, W.; Yang, X.; Huo, M.; Sun, J. High-Performance TiO2 Nanotubes/Poly(aryl ether sulfone) Hybrid Self-Cleaning Anti-Fouling Ultrafiltration Membranes. Polymers 2019, 11, 555. [CrossRef]

39. McCutcheon, J.R.; Elimelech, M. Influence of concentrative and dilutive internal concentration polarization on flux behavior in forward osmosis. J. Membr. Sci. 2006, 284, 237-247. [CrossRef]

40. Geng, Z.; Yang, X.; Boo, C.; Zhu, S.; Lu, Y.; Fan, W.; Huo, M.; Elimelech, M.; Yang, X. Self-cleaning anti-fouling hybrid ultrafiltration membranes via side chain grafting of poly(aryl ether sulfone) and titanium dioxide. J. Membr. Sci. 2017, 529, 1-10. [CrossRef]

41. Sun, H.Z.; Wu, P.Y. Tuning the functional groups of carbon quantum dots in thin film nanocomposite membranes for nanofiltration. J. Membr. Sci. 2018, 564, 394-403. [CrossRef]

42. Liu, Y.; Yu, Z.; Li, X.; Shao, L.; Zeng, H. Super hydrophilic composite membrane with photocatalytic degradation and self-cleaning ability based on LDH and g-C3N4. J. Membr. Sci. 2021, 617, 118504. [CrossRef]

43. Pan, D.; Jiao, J.; Li, Z.; Guo, Y.; Feng, C.; Liu, Y.; Wang, L.; Wu, M. Efficient Separation of Electron-Hole Pairs in Graphene Quantum Dots by TiO2 Heterojunctions for Dye Degradation. ACS Sustain. Chem. Eng. 2015, 3, 2405-2413. [CrossRef] 
44. Jia, H.; Wang, Z.; Yuan, T.; Yuan, F.; Li, X.; Li, Y.; Tan, Z.A.; Fan, L.; Yang, S. Electroluminescent Warm White Light-Emitting Diodes Based on Passivation Enabled Bright Red Bandgap Emission Carbon Quantum Dots. Adv. Sci. 2019, 6, 1900397. [CrossRef] [PubMed]

45. Zhou, S.; Feng, X.; Zhu, J.; Song, Q.; Yang, G.; Zhang, Y.; van der Bruggen, B. Self-cleaning loose nanofiltration membranes enabled by photocatalytic Cu-triazolate MOFs for dye/salt separation. J. Membr. Sci. 2021, 623, 119058. [CrossRef]

46. Xiao, Y.; Guo, D.; Li, T.; Zhou, Q.; Shen, L.; Li, R.; Xu, Y.; Lin, H. Facile fabrication of superhydrophilic nanofiltration membranes via tannic acid and irons layer-by-layer self-assembly for dye separation. Appl. Surf. Sci. 2020, 515, 146063. [CrossRef]

47. Yu, J.; Wang, Y.; He, Y.; Gao, Y.; Hou, R.; Ma, J.; Zhang, L.; Guo, X.; Chen, L. Calcium ion-sodium alginate double cross-linked graphene oxide nanofiltration membrane with enhanced stability for efficient separation of dyes. Sep. Purif. Technol. 2021, 276, 119348. [CrossRef]

48. Li, J.; Li, L.; Xu, Y.; Zhu, J.; Liu, F.; Shen, J.; Wang, Z.; Lin, J. MXene nanosheet stacks with tunable nanochannels for efficient molecular separation. Chem. Eng. J. 2022, 427, 132070. [CrossRef]

49. Zhang, L.; Guan, H.; Zhang, N.; Jiang, B.; Sun, Y.; Yang, N. A loose NF membrane by grafting TiO2-HMDI nanoparticles on PES/ $\beta$-CD substrate for dye/salt separation. Sep. Purif. Technol. 2019, 218, 8-19. [CrossRef]

50. Guo, Q.; Wu, X.; Ji, Y.; Hao, Y.; Liao, S.; Cui, Z.; Li, J.; Younas, M.; He, B. pH-responsive nanofiltration membrane containing chitosan for dye separation. J. Membr. Sci. 2021, 635, 119445. [CrossRef]

51. Yang, L.; Wang, Z.; Zhang, J. Zeolite imidazolate framework hybrid nanofiltration (NF) membranes with enhanced permselectivity for dye removal. J. Membr. Sci. 2017, 532, 76-86. [CrossRef] 